\title{
Sulfated polysaccharides from Phaeodactylum tricornutum: isolation, structural characteristics, and inhibiting HepG2 growth activity in vitro
}

\author{
Shengfeng Yang ${ }^{\text {Corresp., }}{ }^{1}$, Haitao Wan ${ }^{1}$, Rui Wang ${ }^{1}$, Daijun Hao ${ }^{\text {Corresp. }}{ }^{1}$ \\ 1 Qingdao Tumor Hospital, Qingdao, China \\ Corresponding Authors: Shengfeng Yang, Daijun Hao \\ Email address: xiaolinchen_79@163.com, haodaijunzhl@163.com
}

Microalgae, eukaryotic unicellular plants, are increasing in demand due to their use as nutraceutical and food supplements. They consisted different kinds of biologically active components such as polysaccharides. On the other hand, cancer is the leading cause of death globally. At present, there is no efficient method to cure it. Therefore, in this work, we extracted polysaccharides from Phaeodactylum tricornutum (PTP), characterized the chemical composition and structure, and investigated its anticancer activity on HepG2 cells. The results showed that PTP was a sulfated polysaccharide with a high Mw of 4810 $\mathrm{kDa}$, and xylose, fucose, glucose and galactose were the main monosaccharides. PTP has significant anticancer activity in a dose-dependent manner (up to $60.37 \%$ at $250 \mathrm{ug} / \mathrm{ml}$ ) according to MTT assays. Furthermore, cycle analysis was carried out to explain its anticancer activity. The results showed that it exhibited anticancer effect mainly through the induction of apoptosis without affecting the cycle and mitosis of HepG2 cells. This might make it a potential drug for anticancer treatment in the future. 
1 Sulfated polysaccharides from Phaeodactylum tricornutum: isolation, structural

2 characteristics, and inhibiting HepG2 growth activity in vitro

3 Shengfeng Yang, Haitao Wan, Rui Wang, Daijun Hao*

4 Qingdao Tumor Hospital, No. 127 Siliu Nan Road, Qingdao, China

5

6 Abstract:

7 Microalgae, eukaryotic unicellular plants, are increasing in demand due to their use as 8 nutraceutical and food supplements. They consisted different kinds of biologically active 9 components such as polysaccharides. On the other hand, cancer is the leading cause of death globally. At present, there is no efficient method to cure it. Therefore, in this work, we extracted polysaccharides from Phaeodactylum tricornutum (PTP), characterized the chemical composition and structure, and investigated its anticancer activity on HepG2 cells. The results showed that PTP was a sulfated polysaccharide with a high Mw of $4810 \mathrm{kDa}$, and xylose, fucose, glucose and galactose were the main monosaccharides. PTP has significant anticancer activity in a dose-dependent manner (up to $60.37 \%$ at $250 \mathrm{ug} / \mathrm{ml}$ ) according to MTT assays. Furthermore, cycle analysis was carried out to explain its anticancer activity. The results showed that it exhibited anticancer effect mainly through the induction of apoptosis without affecting the cycle and mitosis of HepG2 cells. This might make it a potential drug for anticancer treatment in the future.

\section{Introduction}

Microalgae are promising source of biomass due to their advantageous features such as their phototropic nature, high growth rate, lack of competition with food crops for arable land, and abundant nutritious components, such as protein, pigments and trace elements(Hamilton et al., 2014; Wang et al., 2015). Therefore, it has been used as feedstock,

*Corresponding author haodaijunzhl@163.com 
27

28

such as in food, feed, functional foods, biofuels, or chemicals integrated in novel biorefinery concepts(Zhu L., 2015; Vandamme et al., 2018). Unlike terrestrial plants, the biologically active compounds extracted from microalgae have shown unique properties, such as antibacterial, antiviral, antifungal, antioxidative, anti-inflammatory, and anti-tumor properties(De Jesus Raposo et al., 2014; Guzman et al., 2003; Hayashi et al. 1996; Kaji et al., 2004; Challouf et al., 2011; De Jesus Raposo et al., 2015). From economical point of view, polysaccharides from algae are promising products due to their abundance in algae(Kraan S., 2012). Polysaccharides can be extracted from algae by several "green" extraction techniques, such as microwaveassisted extraction(Rodriguez-Jasso et al., 2011) and enzyme-assisted extraction methods(Ko et al., 2012). The characteristics of different polysaccharides from microalgae, including their composition and structure, were discussed(De Jesus Raposo et al., 2014). It was reported that G. impudicum and C. vulgaris contained homo galactose(Yim et al., 2007) and glucose(Nomoto et al., 1983), respectively. However, the other polysaccharides from microalgae are heteropolymers of galactose, xylose, glucose, rhamnose, fucose and fructose(Matsui et al., 2003; Talyshinsky et al., 2002; Raposo et al., 2014). Ford and Percival(1965) found that the structure of the polysaccharides from Phaeodactylum tricornutum was a ramified sulfated flucoronomannan, with a backbone composed of $\beta$-(1,3)-linked mannose. Many studies have shown that the polysaccharides from microalgae are characterized by antibacterial, antitumor and antiviral properties(Michalak et al., 2015).

As a kind of diatom, Phaeodactylum tricornutum has been found in great abundance in coastal and oceanic waters(Bautista-Chamizo et al., 2018). It contains approximately 36.4\% crude protein, $26.1 \%$ carbohydrate, $18.0 \%$ lipid, $15.9 \%$ ash, and $0.25 \%$ neutral detergent fiber on a dry weight (dw) basis(Rebolloso-Fuentes et al., 2001). In addition, it can accumulate valuable pigments such as fucoxanthin, triacylglycerols, and omega-3 long-chain polyunsaturated fatty acids, such as eicosapentaenoic acid(EPA; C20:5)(Kim et al., 2012; Ryckebosch et al., 2012; Yu et al., 2009; McClure et al., 2018). Currently, it is commercialized for its lipids, especially eicosapentaenoic acid (EPA), and several studies have sought to increase the production yield of 
54

55

56

EPA and biomass(Grima et al., 1994; Alías et al., 2004; McClure et al., 2018). In recent years, due to its many therapeutic activities, fucoxanthin has been commercialized from Phaeodactylum tricornutum. However, there is little research about the polysaccharides extracted from Phaeodactylum tricornutum. Therefore, to make full use of the alga, in this paper, we extracted polysaccharides from Phaeodactylum tricornutum, characterized its chemical structure, and studied the anticancer activity of the polysaccharides.

\section{MATERIALS AND METHODS}

\subsection{Phaeodactylum tricornutum samples and reagents}

Dried Phaeodactylum tricornutum powder was supplied by the Institute of Oceanology, Chinese Academy of Sciences. All the reagents used were of analytical grade and commercially available unless otherwise stated.

\subsection{Extraction of polysaccharides from Phaeodactylum tricornutum (PTP)}

The extraction diagram was as Fig.1.

Fig.1 The extraction diagram of PTP

The dried Phaeodactylum tricornutum powder was extracted by the Soxhlet method with ethanol to remove pigments and lipids. The residue was then dried in an oven at $50^{\circ} \mathrm{C}$, and polysaccharides were extracted by hot distilled water with the assistance of ultrasonic methods. The optimal temperature, times of ultrasonic treatment and extraction time were determined (shown in supplement data). According to the optimal conditions, the residue algal powder was treated by the ultrasonic method for 20 times, 10 seconds working, 10 seconds rest, and $380 \mathrm{~W}$ power. Then, it was extracted at $80^{\circ} \mathrm{C}$ for $2 \mathrm{~h}$ with stirring. The solution produced by filtration was condensed by rotary evaporator and dialyzed for salt removal. The obtained solution was condensed again, and the final solution was freeze-dried to get the purified sulfated polysaccharides, called PTP.

\subsection{Chemical characterization}


81

The Mw of PTP was measured by HPLC with a TSK gel G4000PWxl column using 0.05 $\mathrm{mol} / \mathrm{L} \mathrm{Na}_{2} \mathrm{SO}_{4}$ as the mobile phase on an Agilent 1260 HPLC system equipped with a refractive index detector. The column temperature was $35^{\circ} \mathrm{C}$, and the flow rate of the mobile phase was 0.5 $\mathrm{ml} / \mathrm{min}$. Dextran standards with a $\mathrm{Mw}$ of $1 \mathrm{KDa}, 5 \mathrm{KDa}, 12 \mathrm{KDa}, 50 \mathrm{KDa}, 80 \mathrm{KDa}, 270 \mathrm{KDa}$ and 670KDa (Sigma, Mendota Heights, MN, USA) were used to calibrate the column.

Total sugars were analyzed by the phenol-sulfuric acid method (Dubois et al., 1956) using galactose as the standard. Sulfated content was determined by the barium chloride gelatin method (Kawai et al., 1969). The molar ratios of the monosaccharide composition were determined according to Sun et al. (2017). 1-phenyl-3-methyl-5-pyrazolone(PMP) pre-column derivation HPLC was used to determine the molar ratio of the monosaccharide composition. Briefly, $10 \mathrm{mg}$ polysaccharide sample was dissolved into $1 \mathrm{ml}$ distilled water. The mixture was hydrolysed in 4mol/L trifluoroacetic acid, followed by neutralization with sodium hydroxide. Then, HPLC was used to determine every monosaccharide composition on a YMC Pack ODS AQ column $(4.6 \mathrm{~mm} \times 250 \mathrm{~mm})$. Mannose, rhamnose, fucose, galactose, xylose, glucose and glucuronic acid from Sigma-Aldrich were used as standards. FT-IR spectra of PTP were determined on a Nicolet-360 FT-IR spectrometer between $400 \mathrm{~cm}^{-1}$ and $4000 \mathrm{~cm}^{-1}$.

\subsection{Evaluation of inhibiting HepG2 growth activity in vitro}

\subsubsection{Cell culture}

HepG2 cells purchased from Kunming Cell Bank, Chinese Academy of Sciences, were cultured in DMEM supplemented with 10\% fetal bovine serum solution, $100 \mathrm{U} / \mathrm{ml}$ penicillin and $100 \mathrm{mg} / \mathrm{ml}$ streptomycin at $37^{\circ} \mathrm{C}$ in a humidified atmosphere containing $5 \% \mathrm{CO}_{2}$.

\section{3.2 Evaluation of inhibiting HepG2 growth activity in vitro}

The cell growth inhibitory activity of PTP with different concentrations(50, 100, 150, 200 and $250 \mathrm{ug} / \mathrm{ml}$ ) was assessed by MTT assay. The cells were seeded in a 96-well plate at a concentration of $1 \times 10^{4}$ cells $/ \mathrm{ml}$ and incubated with various concentrations PTP for $48 \mathrm{~h}$. Then, 
107

108

109

110

111

112

113

114

115

116

117

200ul $0.5 \mathrm{mg} / \mathrm{ml}$ MTT solution was added to each well. After $4 \mathrm{~h}$ incubation, the plates were centrifuged for $10 \mathrm{~min}$ at $8000 \mathrm{rpm}$. MTT solution was removed. And 200ul DMSO was added into each well. The absorbance at 570nm was determined.

\subsubsection{Apoptosis assessment}

The apoptosis states of HepG2 cells were determined by an Annexin V-FITC/PI apoptosis kit. Cells were collected and washed with ice-cold PBS twice. Then, the cells were resuspended and diluted to $1 \times 10^{6}$ cell $/ \mathrm{mL}$ with binding buffer. The suspended cells were dyed by $10 \mu \mathrm{L}$ of Annexin V-FITC for $30 \mathrm{~min}$ at room temperature and then stained with $5 \mu \mathrm{L}$ of PI for 5 min. After incubation, the apoptosis of cells was determined by flow cytometry with Guava ${ }^{\circledR}$ easyCyte 6-2L (Millipore, Billerica, MA, USA).

\subsubsection{Analysis of the cell cycle}

A cell cycle analysis kit (Beyotime, China) was used to analyze the cell cycle according to the manufacturer's instructions. Briefly, cells were plated in DMEM with different concentrations of sample for $24 \mathrm{~h}$. Then, both the suspension and the adherent cells were collected and placed into the flow cytometry tube and centrifuged at $1500 \mathrm{rpm}$ for 5 min to obtain cell pellets. After that, the cell pellets were washed with precooling PBS and fixed in icecold $70 \%$ ethanol overnight at $4{ }^{\circ} \mathrm{C}$. Fixed cells were rewashed with PBS and incubated with propidium iodide $(\mathrm{PI})$ staining solution $(0.5 \mathrm{~mL}$ of staining buffer, $25 \mu \mathrm{L}$ of PI staining solution, and $10 \mu \mathrm{L}$ of RNAase A) for $30 \mathrm{~min}$ at $37^{\circ} \mathrm{C}$ in the dark. Cell cycle analysis was carried out with Guava ${ }^{\circledR}$ easyCyte 6-2L (Millipore, Billerica, MA, USA) using 10,000 counts per sample. The percentage of cells distributed in the different phases of G0/G1, S and G2/M were recorded and analyzed.

\subsection{Statistical analysis}

All data are shown as means $\pm \mathrm{SD}$ (standard deviation) of three independent experiments to ensure the reproducibility of the results. Statistical analysis was performed using SPSS. The difference among groups was analyzed by one-way ANOVA. 
134

135

136

137

138

139

140

141

142

143

144

\section{Results}

\subsection{Chemical characterization}

PTP was extracted and purified from Phaeodactylum tricornutum, with a yield of 1.5\%(\% dry weight). It was further characterized regarding $\mathrm{Mw}$, total sugars, sulfate content and monosaccharide composition (Table 1).

According to Table 1, the total sugar and sulfate contents were $29.94 \%$ and $20.36 \%$, respectively, which indicated that PTP was a type of sulfated polysaccharide. The Mw of PTP was higher $(4810 \mathrm{kDa})$. The results of the monosaccharide composition showed that the most common monosaccharide of PTP was xylose, followed by fucose, glucose and galactose, with a small amount of rhamnose. The glucuronic acid content of PTP (0.68) was higher. These results indicated that PTP was a hybrid and acidic polysaccharide.

To further characterize the chemical structure of PTP, the corresponding FT-IR spectrum was examined (Fig. 2). The $\mathrm{O}-\mathrm{H}$ stretching vibration appeared at $3272 \mathrm{~cm}^{-1}$, and the $\mathrm{C}-\mathrm{H}$ stretching vibration appeared at $2926 \mathrm{~cm}^{-1}$. The adsorption at $1632 \mathrm{~cm}^{-1}$ and $1408 \mathrm{~cm}^{-1}$ represented the asymmetric and symmetric stretching vibration of $\mathrm{C}=\mathrm{O}$, respectively. The adsorption at $1226 \mathrm{~cm}^{-}$ 1 and $1038 \mathrm{~cm}^{-1}$ corresponded to the $\mathrm{S}=\mathrm{O}$ stretching vibration and $\mathrm{C}-\mathrm{O}-\mathrm{H}$ deformation vibration, respectively. These results further indicated that PTP was an acidic and sulfated polysaccharide, which chelated with other positive ions.

\section{Fig.2 FT-IR spectra of PTP}

\subsection{Evaluation of inhibiting HepG2 growth activity in vitro}

\section{Fig.3 The effect of different concentration PTP on the inhibition rate of HepG2 by MTT} assay for $48 \mathrm{~h}$

Fig. 3 shows the inhibitory effect of different concentrations of PTP on HepG2 tumor cells. The results indicated that PTP had an antiproliferative effect on HepG2 cells in a dose-dependent manner. With concentration increasing, PTP had higher inhibitory activity, and the inhibition rate was up to $60.37 \%$ when the concentration was $250 \mathrm{ug} / \mathrm{ml}$. However, the manner of PTP 
161 inhibiting HepG2 growth was not clear. To analyze the main cause, we determined the cell 162 apoptosis and cell cycle by flow cytometry.

163

164

165

166

167

168

169

170

171

172

173

174

175

\subsection{Induction of apoptosis according to cell cycle analysis}

Fig.4 The cell apoptosis rate under different concentration of PTP Fig.5 The cell cycle rate under different concentration of PTP

Fig. 4 shows the results of flow cytometry, when the HepG2 cells were treated with different concentrations of PTP. From the results, we deduced the apoptosis rate under different concentrations of PTP (shown in Fig. 4). From Fig. 4, when HepG2 cells were treated with PTP, the apoptosis rate increased in a dose-dependent manner, although it decreased slightly under $200 \mathrm{ug} / \mathrm{ml}$ PTP. When the concentration of PTP was $250 \mathrm{ug} / \mathrm{ml}, 30 \%$ apoptosis of cells was induced. Double negative PI-Annexin V cells accounted for about $63 \%$. The above results were consistent with those of the MTT assay. They indicated that PTP could significantly induce cell apoptosis. Then, we determined the HepG2 cell cycle rate under three different concentrations (50 ug/ml, $150 \mathrm{ug} / \mathrm{ml}$ and $250 \mathrm{ug} / \mathrm{ml}$ ) of PTP, as shown in Fig. 5. From Fig. 5, the treatment of different concentrations of PTP did not influence the HepG2 cell cycle rate, which might indicate that PTP's anticancer effect occurred mainly through induction of apoptosis without affecting the mitosis of HepG2 cells.

\section{Discussion}

Cancer is the leading threat to the world population, and it is the first-leading cause of death worldwide. The current cancer treatments often cause side effects(Samarakoon et al., 2014; Boopathy et al., 2010). Recently, due to their favorable properties, polysaccharides from microalgae have been given increased attention. Polysaccharides from Spirulina platensis have been shown to have antitumor functions on human HT-29 cells $(X u$ et al., 2012a), MB-231 cells(Xu et al., 2012b), HeLa cells(Yu et al., 2003) and HepG2 cells(Di et al., 2013). Polysaccharides from Platymonas subcondigoramis inhibited melanoma(Liu et al., 2007). 
Umemura et al. (2003) showed that polysaccharides from the dinoflagellate Gymnodinium sp. exhibited significant cytotoxicity against a variety of cancer cells, which meant that the polysaccharides might be a potential anticancer chemotherapeutic agent. For Phaeodactylum tricornutum, some references reported antioxidant(Agustini et al., 2017), anti-obesity(Kim et al., 2016), anti-inflammatory and immunomodulatory activities(Kim et al., 2013; Guzmán et al., 2003). A novel fatty alcohol ester isolated from Phaeodactylum tricornutum showed apoptotic anticancer activity(Samarakoon et al., 2014). Few studies have addressed polysaccharides isolated from Phaeodactylum tricornutum. Agustini et al.(2017) extracted endoexopolysaccharide and determined its antioxidant activity on DPPH. The composition of the polysaccharides included xylose, glucose and galactose. Similarly, the monosaccharide composition of PTP mainly included xylose, fucose, glucose and galactose. Fucose was not reported by Agustini et al.(2017), which may be due to the different origins of the algae. In this paper, we determined not only the monosaccharide composition but also the total sugar, sulfate contents and $\mathrm{Mw}(29.94 \%, 20.36 \%$ and $4810 \mathrm{kDa}$, respectively) and found that PTP is a complicated sulfated polysaccharide. A type of lipopolysaccharide extracted from Phaeodactylum tricornutum exhibited anti-inflammatory activity by blocking the activation of nuclear factor- $\mathrm{kB}$ and phosphorylation of p38 mitogen-activated protein kinases, extracellular signal-regulated kinases 1 and 2 and c-Jun N-terminal kinase(Kim et al., 2013). However, there was no related information about the lipopolysaccharide. To our knowledge, no anticancer activity has been reported for PTP. In this paper, we determined the anticancer activity of PTP on HepG2 cells. Significant anticancer activity (up to $60.37 \%$ under $250 \mathrm{ug} / \mathrm{ml}$ ) by MTT assays, which was much better than for polysaccharides isolated from Spirulina platensis(Xu et al., 2012a; Xu et al., 2012b).

In addition, several studies reported that polysaccharides isolated from Spirulina platensis exhibited anticancer activity by blocking G0/G1 phase of cancer cells, which induced the mitosis of cancer cells and led to apoptosis of the cells(Xu et al., 2012a; Xu et al., 2012b; Yu et al., 2003; Di et al., 2013). However, in this paper, although the apoptosis rate of HepG2 cells increased, 
215

216

217

218

219

220

221

222

223

224

225

226

227

228

229

230

231

232

233

234

235

236

237

238

239

240

241

cell cycle analysis indicated that PTP's anticancer effect occurred mainly through induction of apoptosis without affecting the cell cycle and mitosis of HepG2 cells. This result might differ according to the chemical components and structure. It needs further investigation. In addition, some references reported that microalgae polysaccharides have the capacity to modulate the immune system so that they display anticancer activity in vivo(Andrade et al., 2018). For this study, only in vitro cell experiments were carried out, and it is necessary to explore the anticancer activity in vivo. Further research will address this issue.

\section{Conclusion}

In this paper, a sulfated polysaccharide (PTP) was extracted from Phaeodactylum tricornutum with a high $\mathrm{Mw}(4810 \mathrm{kDa})$. The monosaccharide composition of PTP was mainly xylose, fucose, glucose and galactose. MTT assays showed that PTP has significant anticancer activity (up to $60.37 \%$ under $250 \mathrm{ug} / \mathrm{ml}$ ). Furthermore, the anticancer effect occurred mainly through induction of apoptosis without affecting the cell cycle and mitosis of HepG2 cells. Thus, PTP may be a potential drug for anticancer treatment.

\section{References}

Agustini NWS, Kusmiati. 2017. Potency of endo-exopolysaccharide from Porphyridium cruentum(S.F.Gray) Nägeli as antioxidant(DPPH) and biological toxicity(BSLT). ICBS conference Proceedings, International Conference on Biological Science(2015), Volume 2017. Alías CB, López MCGM, Fernández FGA, Sevilla JMF, Sánchez JLG, Grima EM. 2004. Influence of power supply in the feasibility of Phaeodactylum tricornutum cultures. Biotechnology and Bioengineering 87(6): 723-733.

Andrade KAM, Lauritano C., Romano G. and Ianora A. 2018. Marine microalgae with anticancer properties. Marine Drugs 16, 165, doi: 10.3390/md16050165.

Bautista-Chamizo E, Sendra M, Cid Á, Seoane M, de Orte MR, Riba I. 2018. Will temperature 
and salinity changes exacerbate the effects of seawater acidification on the marine microalga Phaeodactylum tricornutum. Science of the Total Environment 634: 87-94.

Boopathy NS and Kathiresan K. 2010. Anticancer drugs from marine flora: an overview. Journal of Oncology 214186, doi: 10.1155/2010/214186.

Challouf R, Trabelsi L, Dhieb RB, El Abed O, Yahia A, Ghozzi K, Ammar JB, Omran H, Ouada HB. 2011. Evaluation of cytotoxicity and biological activities in extracellular polysaccharides released by cyanobacterium Arthrospira platensis. Brazilian Archives of Biology and Technology 54: 831-838.

De Jesus Raposo MF, de Morais AMMB, de Morais RMSC. 2014. Bioactivity and application of polysaccharides from marine microalgae. In polysaccharides: Bioactivity and Biotechnology; Merillon JM, Ramawat KG. Eds: Springer, Cham, Switzerland, doi: 10.1007/978-3-31903751-6 47-1.

De Jesus Raposo MF, de Morais AMB and de Morais RMSC. 2015. Marine polysaccharides from algae with potential biomedical applications. Marine Drugs 13: 2967-3028.

Di JX, Wang J. 2013. Experimental study of Spirulina polysaccharides on the proliferation and apoptosis rate of hepatoma carcinoma cells induced by radiation. Western Journal of Traditional Chinese Medicine 26(7): 20-22.

Dubois M, Gilles KA, Hamilton JK, Rebers PA, Smith F. 1956. Colorimetric method for determination of sugars and related substances. Analytical Chemistry 28: 350-356.

Ford CW, Percival E. 1965. The carbohydrates of Phaeodactylum tricornutum. Part I. Preliminary examination of the organism and characterization of low molecular weight material and of a glucan. Journal of the Chemical Society 1298: 7035-7041.

Guzmán S, Gato A, Lamela M, Freire-Garabal M and Calleja JM. Anti-inflammatory and immunomodulatory activities of polysaccharide from Chlorella stigmatophora and Phaeodactylum tricornutum. Phytotherapy Research 17: 665-670.

Hamilton ML, Haslam RP, Napier JA, Sayanova O. 2014. Metabolic engineering of Phaeodactylum tricornutum for the enhanced accumulation of omega-3 long chain 
269

270

271

272

273

274

275

276

277

278

279

280

281

282

283

284

285

286

287

288

289

290

291

292

293

294

295

polyunsaturated fatty acids. Metabolic engineering 22: 3-9.

Hayashi T, Hayashi K, Maeda M, Kojima I. 1996. Calcium spirulan, an inhibitor of enveloped virus replication, from a blue-green alga Spirulina platensis. Journal of Natural Products 59: 83-87.

Grima EM, Perez JAS, Camacho FG, Fernandez FGA, Sevilla JMF, Sanz FV. 1994. Effect of dilution rate on eicosapentaenoic acid productivity of Phaeodactylum tricornutum utex 640 in outdoor chemostat culture. Biotechnology Letters 16(10): 1035-1040.

Kaji T, Okabe M, Shimada S, Yamamoto C, Fujiwara Y, Lee JB, Hayashi T. 2004. Sodium spirulan as a potent inhibitor of arterial smooth muscles cell proliferation in vitro. Life Sciences 74: 1-9.

Kawai Y, Seno N, Anno KA. 1969. A modified method for chondrosulfatase assay. Analytical Biochemistry 32: 314-321.2017.

Kim SM, Jung YJ, Kwon ON, Cha KH, Um BH, Chung DH, Pan CH. 2012. A potential commercial source of fucoxanthin extacted from the microalga Phaeodactylum tricornutum. Applied Biochemistry and Biotechnology 166:1843-1855Ko SC, Lee SH, Ahn G, Kim KN, Cha SH, Jeon BT, Park PJ, Lee KW, Jeon YJ. 2012. Effects of enzyme-assisted extract of Sargassum coreanum on induction of apoptosis in HL-60 tumor cells. Journal of Applied Phycology 24(4): 675-684.

Kim JH, Kim SM, Pan CH, Choi JK, Lee JK. 2013. Evaluation of anti-inflammatory activities and mechanisms of microalga Phaeodactylum tricornutum. Journal of Biological Chemistry 56(2): 61-67.

Kim JH, Kim SM, Cha KH, Mok IK, Koo SY, Pan CH, Lee JK. 2016. Evaluation of the antiobesity effect of the microalga Phaeodactylum tricornutum. Applied Biological Chemistry 59(2): 283-290.

Kraan S. 2012. Algal polysaccharides, novel applications and outlook, in: Chang, C.-F.(Ed.), Carbohydrates-Comprehensive studies on glycobiology and Glycotechnology, Intech, Rijeka, Croatia, pp. 489-532. 
296 Liu Y, Yang HB, Zhao LH, Yu Y, Li YM, Lv FR. 2007. Separation and analysis of 297 polysaccharide from P. subcordigoramis(Will) hanzen and primary studies on it's anticancer 298 activity. Biotechnology(In Chinese) 3: 53-56.

299 Matsui SM, Muizzudin N, Arad SM, Marenus K. 2003. Sulfated polysaccharides from red 300 microalgae anti-inflammatory properties in vitro and in vivo. Applied Biochemistry and 301 Biotechnology 104: 13-22.

302 McClure DD, Luiz A, Gerber B, Barton GW, Kavanagh JM. 2018. An investigation into the 303 effect of culture conditions on fucoxanthin production using the marine microalgae 304 Phaeodactylum tricornutum. Algal Research 29: 41-48.

305 Michalak I, Chojnacka K. 2015. Algae as production systems of bioactive compounds. 306 Engineering in Life Sciences 15: 160-176.

307

308

309

310

311

312

313

314

315

316

317

318

319

320

321

322

Nomoto K, Yokokura T, Satoh H, Mutai M. 1983. Anti-tumor effect by oral administration of Chlorella extract, PCM-4 by oral admission. Gan To Kagaku Zasshi 10: 781-785. (In Japanese)

Raposo MFJ, Morais AMMB, Morais RMSC. 2014. Influence of sulphate on the composition and antibacterial and antiviral properties of the exopolysaccharide from Porphyridium cruentum. Life Sciences 101: 56-73.

Rebolloso-Fuentes MMM, Navarro-Pérez A, Ramos-Miras JJ, Guil-Guerrero JL. 2001. Biomass nutrient profiles of the microalga Phaeodactylum tricornutum. Journal of Food Biochemistry 25: 57-76.

Rodriguez-Jasso RM, Mussatto SI, Pastrana L, Aguilar CN, Teixeira JA. 2011. Microwaveassisted extraction of sulfated polysaccharides(fucoidan) from brown seaweed. Carbohydrate Polymers 86: 1137-1144.

Ryckebosch E, Bruneel C, Muylaert K, Foubert I. 2012. Microalgae as an alternative source of omega-3 long chain polyunsaturated fatty acids. Lipid Technology 24: 128-130.

Samarakoon KW, Ko JY, Lee JH, Kwon OM, Kim SW, Jeon YJ. 2014. Apoptotic anticancer activity of a novel fatty alcohol ester isolated from cultured marine diatom, Phaeodactylum tricornutum. Journal of Functional Foods 6: 231-240. 
323 Sun YH, Chen XL, Cheng ZQ, Liu S, Yu HH, Wang XQ and Li PC. 2017. Degradation of 324 Polysaccharides from Grateloupia filicina and their antiviral activity to avian Leucosis virus 325 subgroup J. Marine Drugs 15, 345; doi: 10.3390/md15110345.

326 Talyshisky MM, Souprun YY, Huleihel MM. 2002. Antiviral activity of red microalgal 327 polysaccharides against retroviruses. Cancer Cell International 2: 8-14.

328 Umemura K, Yanase K, Suzuki M, Okutani K, Yamori T, Andoh T. 2003. Inhibition of DNA

329 topoisomerases I and II, and growth inhibition of human cancer cell lines by a marine 330 microalgal polysaccharide. Biochemist Pharmacology 66: 481-487.

Vandamme D, Gheysen L, Muylaert K, Foubert I. 2018. Impact of harvesting method on total 332 lipid content and extraction efficiency for Phaeodactylum tricornutum. Separation and Purification Technology 194: 362-367.

334

335

336

337

338

339

340

341

342
Wang X, Liu YH, Hu DX, Balamurugan S, Lu Y, Yang WD, Liu JS, Li HY. 2015. Identification of a putative patatin-like phospholipase domain-containing protein 3(PNPLA3) ortholog involved in lipid metabolism in microalga Phaeodactylum tricornutum. Algal research 12: 274-279.

Xu XJ, Zhang Y, Tang C, Ge W, Liu YJ, Wang QJ. 2012a. Antitumor function of compound polysaccharides from Spirulina platensis on human HT-29 cell line in vitro. Lishizhen Medicine and Materia Medica Research 23(9): 2164-2166.

Xu XJ, Zhang Y, Tang C, Ge W, Liu YJ, Wang QJ. 2012b. Antitumor function of compound polysaccharides from Spirulina platensis on humanMB-231 cell line in vitro. Journal of Liaoning University of TCM 14(10): 70-72.

Yim JH, Kim SJ, Ahn SH, Lee HK. 2007. Characterization of a novel bioflocculant, p-KG03, from a marine dinoflagellate, Gyrodinium impudicum KG03. Bioresource Technology 98: 361-367.

Yu H, Zhang XC. 2003. Effect of polysaccharide from Spirulina platensis on the growth of Hela cells. Chinese Journal of Marine Drugs 1: 26-29.

Yu ET, Zendejas FJ, Lane PD, Gaucher S, Simmons BA, Lane TW. 2009. Triacylglycerol 
350 accumulation and profiling in the model diatoms Thalassionsira pseudonana and 351 Phaeodactylum tricornutum(Baccilariophyceae) during starvation. Journal of Applied 352 Phycology 21: 669-681.

353 Zhu L. 2015. Biorefinery as a promising approach to promote microalgae industry: an innovative 354 framework. Renewable \& nergy reviews 41: 1376-1384.

355 
Figure 1

Extraction process

The extraction diagram of PTP

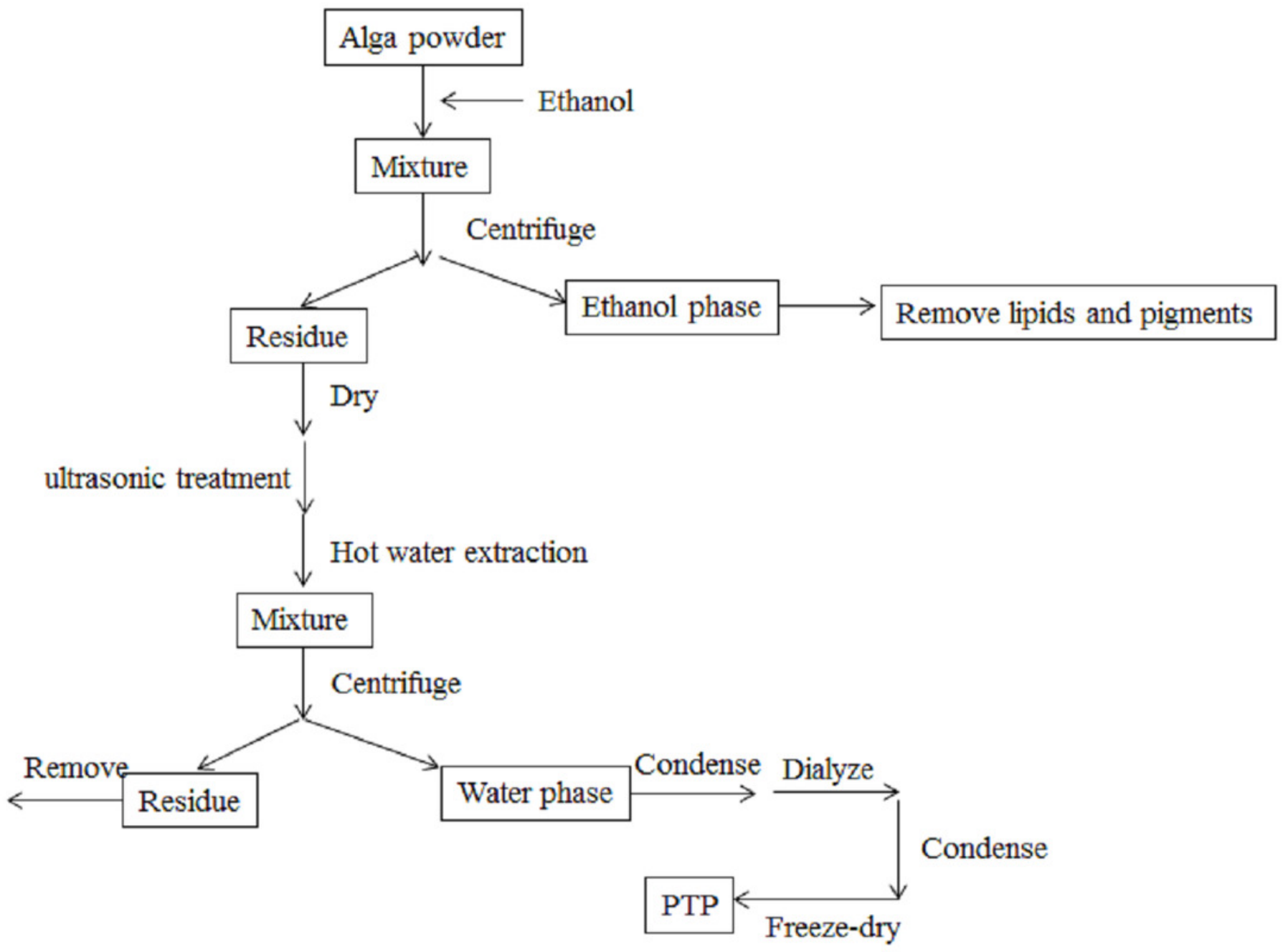

Fig.1 The extraction diagram of PTP 
Figure 2

FTIR

Fig.2 FT-IR spectra of PTP

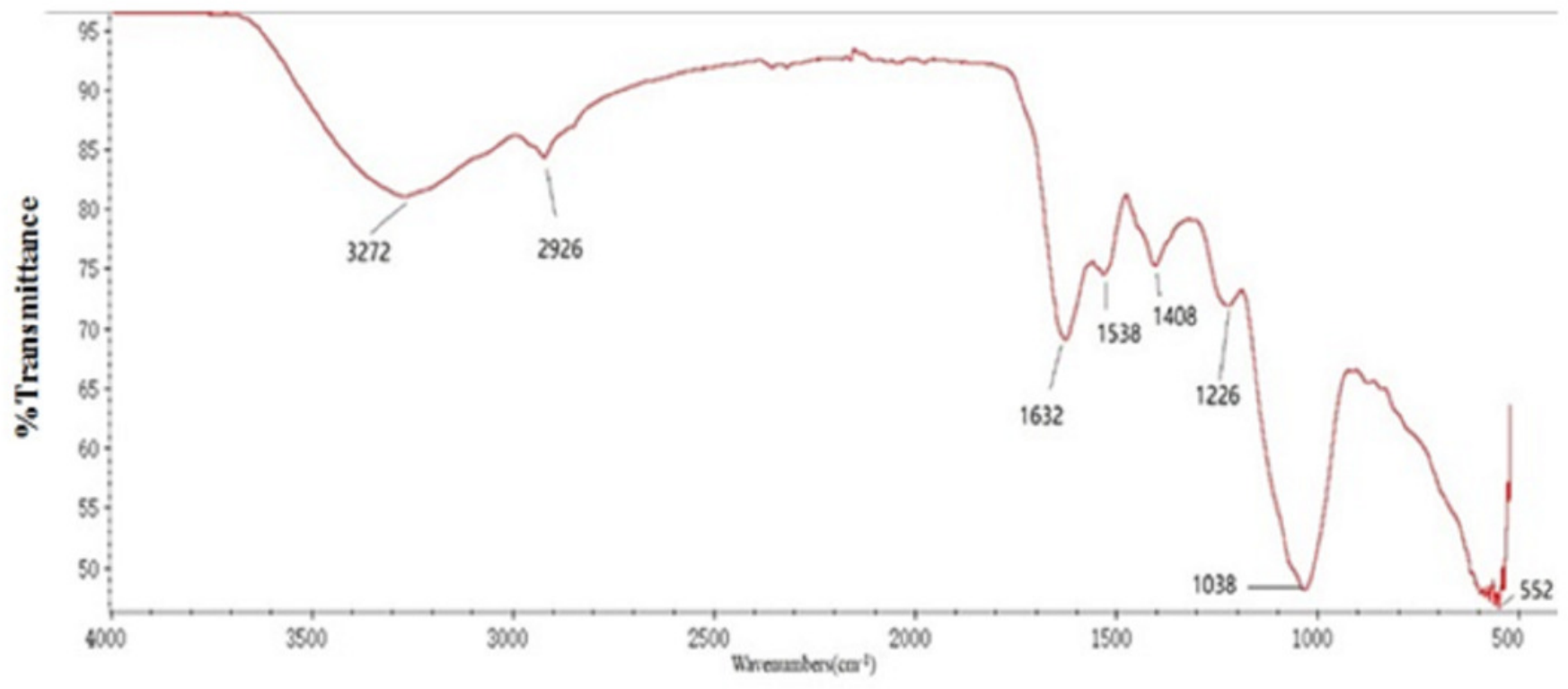

Fig.2 FT-IR spectra of PTP 
Figure 3

inhibition rate of HepG2 by MTT assay

Fig. 3 The effect of different concentration PTP on the inhibition rate of HepG2 by MTT assay for $48 h$

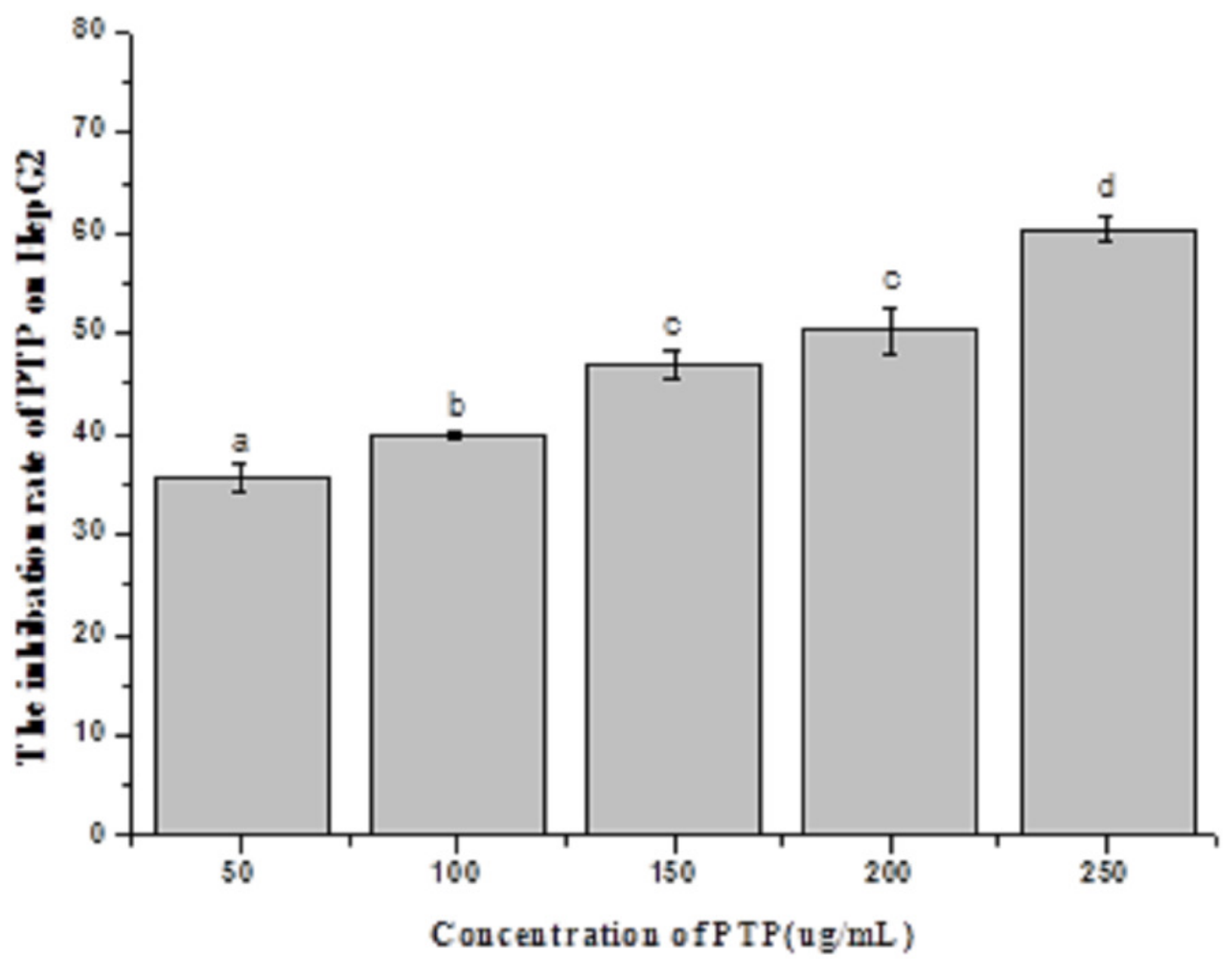

Fig.3 The effect of different concentration PTP on the inhibition rate of HepG2 by MTT assay for $48 \mathrm{~h}$ 
Figure 4

cell apoptosis rate

Fig.4 The cell apoptosis rate under different concentration of PTP

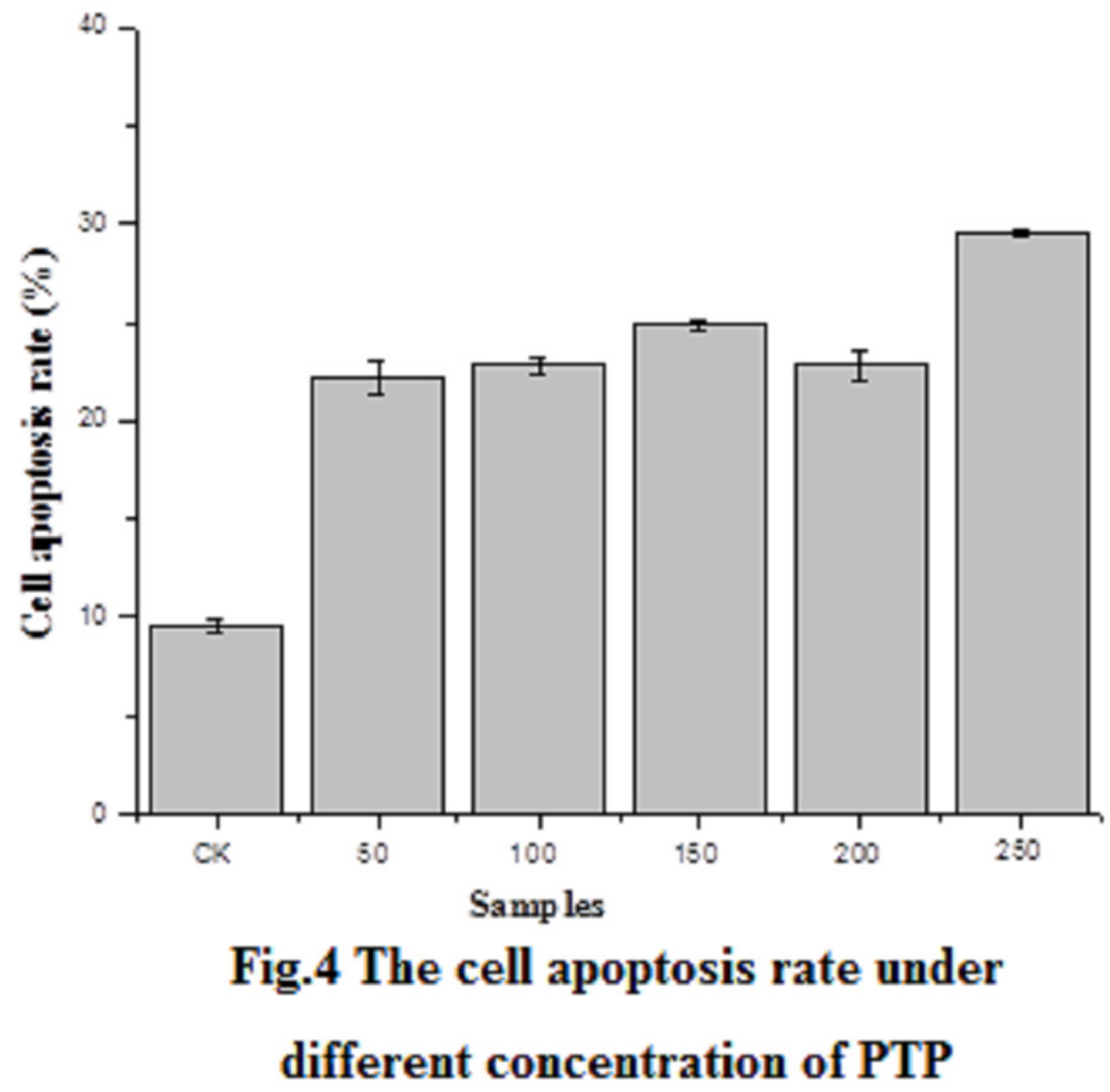


Figure 5

cell cycle

Fig.5 The cell cycle rate under different concentration of PTP

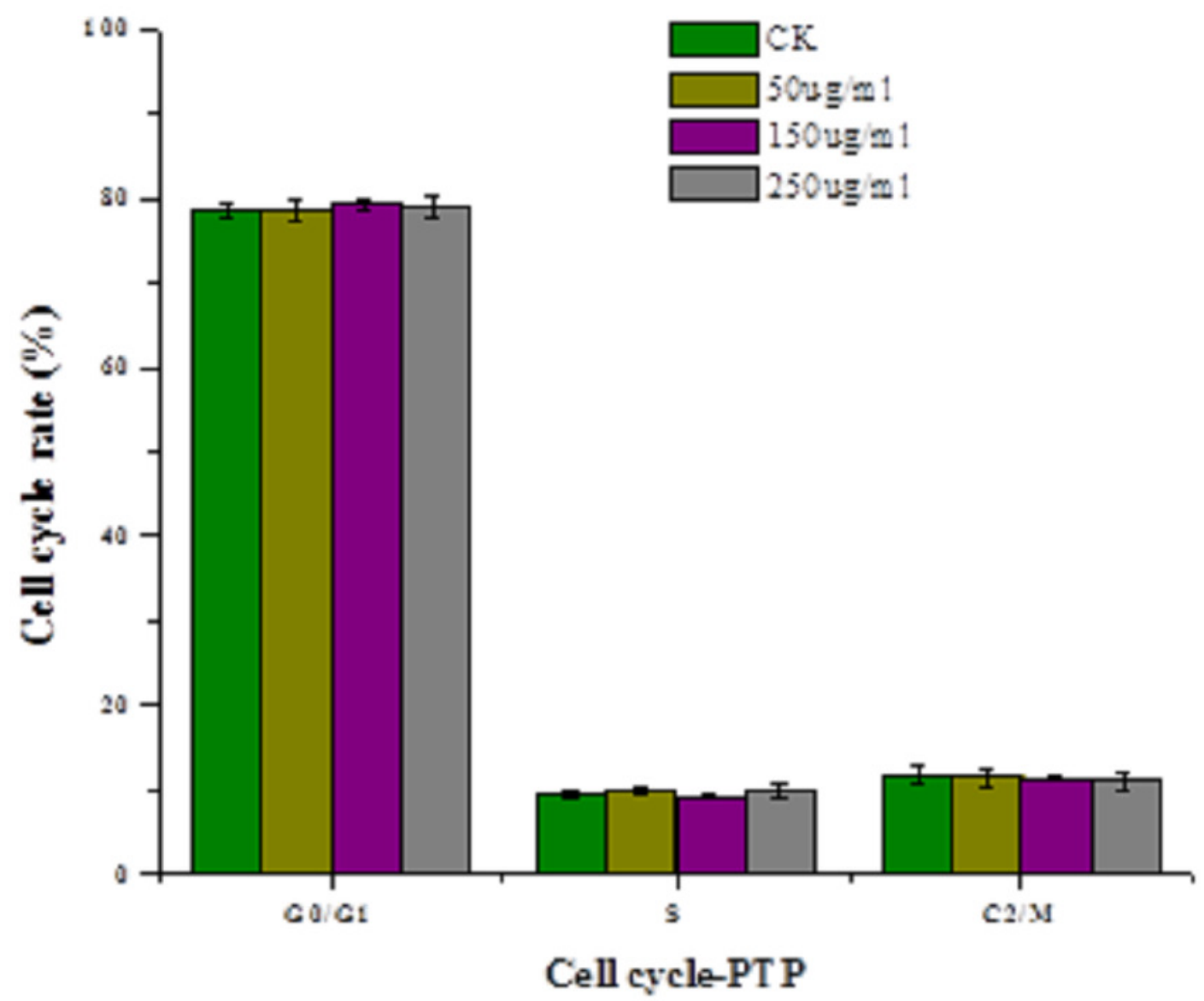

Fig.5 The cell cycle rate under different concentration of PTP 


\section{Table 1 (on next page)}

Chemical composition

Chemical composition of PTP(\%w/w dry weight) 
1 Table:

2 Table 1 Chemical composition of PTP(\%w/w dry weight $)$

\begin{tabular}{ccccccccccc}
\hline \multirow{2}{*}{ Sample } & $\begin{array}{c}\text { Total } \\
\text { sugar/\% }\end{array}$ & \multirow{2}{*}{ Sulfate/\% } & \multirow{2}{*}{ Mw/kDa } & \multicolumn{6}{c}{ Monosaccharides Composition (Molar Ratio) } \\
\cline { 5 - 11 } & & & Man & Rha & Glc A & Glc & Gal & Xyl & Fuc \\
\hline PTP & 29.94 & 20.36 & 4810 & 0.00 & 0.25 & 0.68 & 0.53 & 0.56 & 1.00 & 0.75 \\
\hline
\end{tabular}

3 Man: mannose; Rha: rhamnose; Glc A: glucuronic acid; Gal: galactose; Glc: glucose;

4 Xyl:xylose; Fuc: fucose

5

6 